\title{
Venae Perforantes: A Clinical Review
}

\author{
Pierre antonius Franciscus Alexius van Neer MD, * Joep Cristianus Jacobus Maria \\ Veraart, MD, $\mathrm{PhD}^{\dagger}$ and Hendrik Arent Martino Neumann, MD, PhD \\ ${ }^{*}$ Laurentius Hospital, Roermond, ${ }^{\dagger}$ University Hospital, Maastricht, and ${ }^{\ddagger}$ Erasmus Medical Center, Rotterdam, the \\ Netherlands
}

BACKGROUND. Although many articles on perforating veins have been published, much knowledge about these veins is lacking. OBJECTIVE. In this review relevant facts about the clinical importance of perforating veins in venous disease are described. METHODS. A literature search on English, French and German articles has been performed using literature databases like Medline, Embase and Cochrane.

RESULTS. Selection criteria are described.

CONCLUSION. A few conclusions are drawn: incompetent perforating veins can be of haemodynamic importance, especially in venous ulceration and (recurrent) varicose veins.
The current definition of incompetent perforating veins is reflux more than 0,5 seconds (detected by Duplex ultra-sonography). Good anatomical and clinical classifications are published and should be integrated in the CEAP classification. Based on the clinical classification treatment options are described for the different types of incompetent perforating veins. Two different treatment modalities for incompetent perforating veins are surgery (SEPS) and sclerotherapy. SEPS seems to be of benefit in patients with venous ulceration and advanced CVI. Sclerotherapy (especially ultra sound guided sclerotherapy) is promising and worth further evaluation.
THE FIRST author who demonstrated perforating veins (PVs) in the lower leg was von Loder, a Russian anatomist. ${ }^{1}$ Many anatomists and clinicians have since then investigated PVs. ${ }^{2-8}$ PVs join the superficial and deep veins of the lower leg and normally direct the blood from the superficial to the deep venous system. They are called PVs because they pierce the fascia generalis. PVs are often duplicated. Along with the PVs runs a small artery. ${ }^{9}$ PVs possess valves (one to four valves) that are mostly located subfascial. ${ }^{2}$ Anatomic studies showed that many PVs with a diameter of less than $1 \mathrm{~mm}$ have no valves. ${ }^{10}$ Valveless PVs probably have no hemodynamic function.

The PVs are thought to play an important role because of their valves in directing the blood flow from the superficial network to the deep veins. ${ }^{11}$ They appear to play the role of pressure valves when a sudden marked increase in pressure occurs in a muscular component. During this pressure increase, the valves in the PV close, and this prevents blood flow from the deep to the superficial system. During relaxation, the pressure decreases, and the valves in the PVs open to allow blood flow from the superficial into the deep system. Although it has always been postulated that the blood flow in PVs goes from the superficial veins to the

Address correspondence and reprint requests to: Pierre Antonius Franciscus Alexius van Neer, Laurentius Ziekenhuis, Postbus 920, 6040 AX Roermond, or e-mail: dermatologie1@lzr.nl. deep veins (so-called inward flow), it was Bjordal ${ }^{12,13}$ who first demonstrated bidirectional flow (inward and outward flow) in PVs in patients with primary varicosis. This bidirectional flow in patients with venous disease was confirmed by others using duplex ultrasonography. ${ }^{14,15}$ Bidirectional flow in PVs has also been detected by duplex ultrasonography in persons without any signs of venous disease, ${ }^{14,16}$ although others could not confirm this. ${ }^{15}$

There are numerous PVs in each lower limb, probably approximately 150 , of variable length. ${ }^{17}$ In a recent consensus document, a proposal was done to use descriptive terms designating the location of PVs. ${ }^{18}$ According to this article, the PVs of the lower limbs can be divided into six groups: PVs of the foot, ankle, leg, knee, thigh, and gluteal muscles. From a clinical point of view, there are four important locations for PVs: the thigh, the upper medial part and the lower medial part of the lower leg, and the knee fold. ${ }^{19}$ In the thigh, we can find the clinical important inguinal perforators (also called the saphenofemoral crosse), connecting the greater saphenous vein (GSV) with the femoral vein in the groin. More distally located in the thigh, the perforators of the femoral canal (also called PVs of Dodd or Hunter) are found, connecting the GSV with the superficial femoral vein, although in some patients, these PVs run different and have no connection with the GSV. $^{20}$ In the upper medial part of the lower leg, the paratibial perforators (also called PVs of Sherman and 
Boyd) connect the GSV with the posterior tibial veins. These PVs are a common site for the spontaneous occurrence of primary and recurrent varicosis. ${ }^{19}$ On the lower medial part of the lower leg, the posterior tibial perforators (also called PVs of Cockett) are of clinical importance. They connect the posterior accessory GSV with the posterior tibial veins. This is the place where most clinical symptoms of chronic venous insufficiency (CVI) occur. The popliteal fossa perforator (also called the parvapopliteal crosse) connects the short saphenous vein with the popliteal vein.

\section{Methods}

A literature search on English, German, and French publications has been performed on venae perforantes or PVs using medical literature databases like Medline, Embase, and Cochrane. Key words used are vena(e) perforan(te)s, vena(e) communican(te)s, PVs and communicating veins, perforan(te)s jambieres, and perforierende vene(n). Reference lists of relevant articles have been reviewed also for additional citations, as were the entire review articles.

Selection criteria for all articles were defined as follows: PVs should have been the main study objective. Clinical aspects of PV should have been investigated. Special attention should have been paid to the possible influence of coexisting superficial incompetence, and whenever the influence or relevance of incompetent PVs (IPV) was investigated, the hemodynamic significance of these IPV should have been investigated with objective methods such as ambulatory venous pressure (AVP), photo-, air- or strain-gauge plethysmography. Evidence in intervention studies depended on the following criteria: level 1 evidence, which was based on one A1 study (defined as a meta-analysis of A2 studies in which the results of several A2 studies are consistent) or two independent A2 studies (defined as randomized, comparative, double-blinded, clinical studies); level 2 evidence, which was based on two independent B studies (defined as randomized studies of poor quality or other comparative studies like case control, cohort); level 3 evidence, which was based on one A2 or one B study or on C studies (defined as noncomparative studies); and level 4 evidence, which was the opinion of experts.

\section{IPVs}

On which criteria do phlebologists decide that a PV is incompetent? There is no agreement about the definition of IPV. ${ }^{10,15,16,21,22}$ The two criteria mostly used to decide whether a PV is incompetent are reflux and diameter. Reflux, or outward flow (defined as flow from deep to superficial system), is considered to be the most reliable criterion to decide whether a PV is incompetent. Although it is known that reflux occurs in healthy subjects as well, it has been shown that the number of PVs showing reflux increases with more and advanced chronic vein disease. ${ }^{15,16,23}$ Reflux must be measured preferably in the relaxation phase after distal compression. ${ }^{14}$ The duration of reflux as a criterion of incompetence varies from 0.3 seconds $^{24}$ to 1 second, ${ }^{25}$ but most authors consider reflux of more than 0.5 second as evidence for incompetence. ${ }^{23,26-29}$ Concerning the diameter, it has been shown that IPVs have a bigger diameter than competent ones. ${ }^{15,23,26}$ Although several authors consider a certain diameter predictive of pathologic reflux, ${ }^{7,10,15,16,26}$ most authors agree that the diameter should not be a criterion to decide whether a PV is competent or incompetent. ${ }^{25}$ Other criteria to describe IPV have also been proposed: In a prospective study by duplex ultrasonography of 265 PVs in 90 legs, Delis ${ }^{23}$ concluded that criteria to discriminate between competent and IPVs are not only reflux and diameter, but also peak and mean velocities, volume flow, time to peak velocity, and venous volume displaced outward. It is clear that more research is needed in order to develop criteria to define and grade incompetence of PVs, using reflux time, number of IPVs, diameter, and several other criteria.

Based on the different pathogenetic ways, PVs may become incompetent; several authors have developed a clinical classification of IPVs. They base this classification on the presence of IPV and reflux in other segments of the venous systems. ${ }^{30-33}$ In summarizing these classifications, one might conclude that there are five clinical different types of IPVs (Table 1).

\section{IPV I: Primary Type}

In this case, there is a primary insufficiency of a PV, probably caused by an inherited weakness of the vein wall. $^{34}$ This IPV leads to an insufficient superficial venous segment distal of this IPV. Varicose veins occurring from such a primary IPVs are known as "perforans varicose." ${ }^{35}$ IPV I are found along the GSV pathway and can cause significant reflux, resulting in medium-sized distal varicositas. ${ }^{36}$ One might consider primary incompetence of the saphenofemoral and parvapopliteal junctions as IPV I. Primary incompetence of the Hunterian perforator vein can also be considered as an IPV I and is known as a common cause of medial thigh varicose veins in patients with a competent saphenofemoral junction. ${ }^{19}$ In fact, Fegan ${ }^{37}$ already described in 1963 that saphenovarices have been found to disappear after injection of an incompetent Hunterian "communicating" vein. Another example of IPV I is primary incompetence of the PV of Boyd. This IPV is considered by some authors as the 
Table 1. Clinical Classification of IPVs (After Stuart, Clerici, Saharay, Rabe)

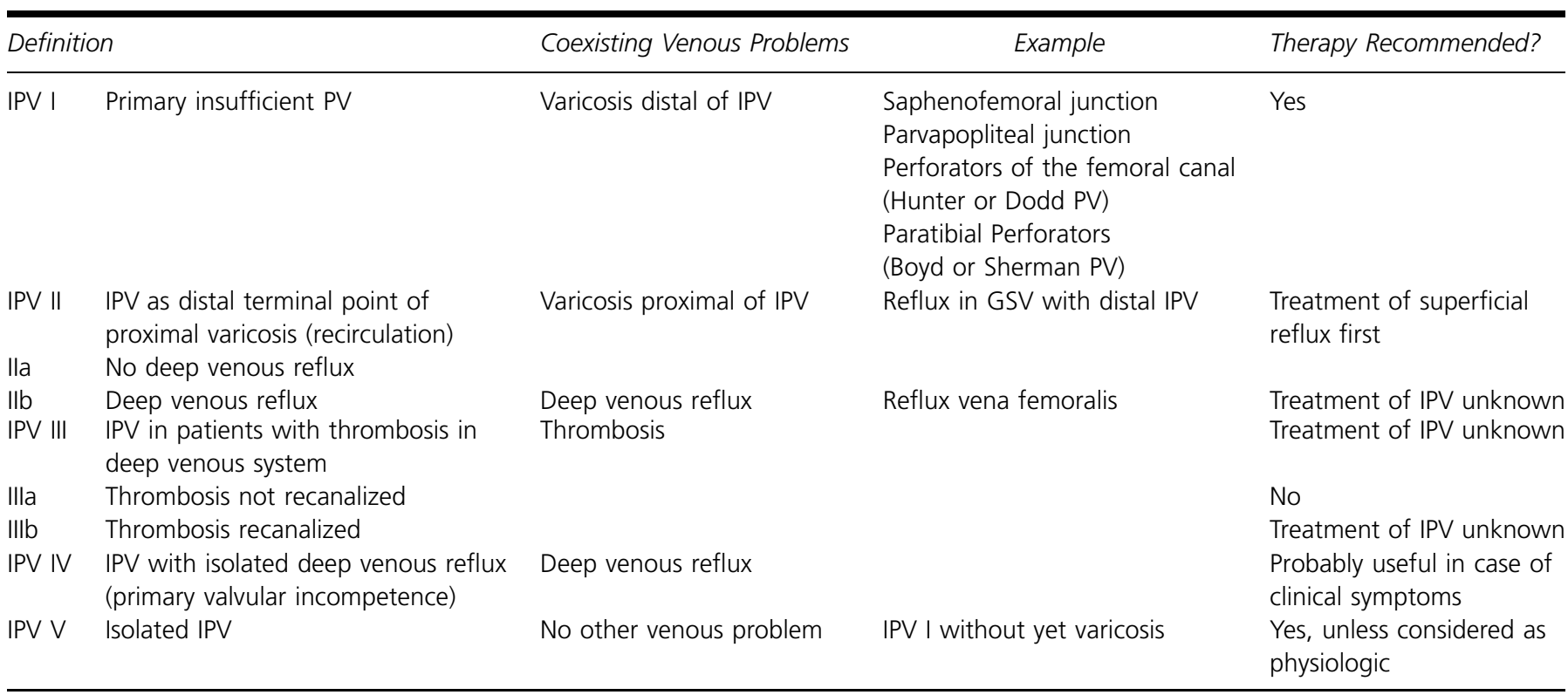

most common side for spontaneous occurrence of a primary varicose vein. ${ }^{19}$

\section{IPV IIa: Secondary to Varicositas, No Evidence of Deep Venous Reflux}

The PV becomes incompetent as a result of a proximally located insufficient superficial venous system. Hach ${ }^{35}$ studied the function of PV in the so-called private circulation (privatkreislauf-rezirkulationskreise), a concept that was first introduced by the surgeon Trendelenburg. ${ }^{38}$ Hach stated that in case of reflux in the superficial system, the deep venous system becomes overloaded. In the early stage, compensation is possible via a private circulation: The blood will re-entry the superficial system through distal competent PVs. These so-called re-entry PVs are considered useful for drainage and cannot be considered as pathological. ${ }^{39}$ They show bidirectional flow, with a resultant flow inward. ${ }^{12,39}$ $\mathrm{Hach}^{35}$ defined this situation as a "compensated" private circulation. When this situation continues to exist, the deep system will become too much overloaded and the distal re-entry PV can become incompetent. IPVs are most likely to be found in association with (correctable) superficial reflux disease, ${ }^{40}$ and therefore, the most common type of IPV is type IIa. ${ }^{15,30}$

\section{IIb: With Evidence of Deep Venous Reflux}

Whenever the superficial reflux and the secondary IPV continue to exist, a secondary insufficiency of the popliteal and femoral veins will develop, and the clinical picture of CVI will become clear. In this situation,
Hach $^{35}$ spoke of an "decompensated" private circulation. It is known that deep vein reflux accompanies saphenous reflux in $20 \%$ of limbs with varicose veins. ${ }^{41}$ Type IIb is the second most common type of IPV. ${ }^{30}$

\section{IPV IIIa: IPV as a Result of Posttrombotic Syndrome, Thrombosis Not Recanalized}

In this situation, the IPV acts as part of a collateral pathway for deep venous obstruction.

\section{IIIb: Thrombosis Recanalized}

The deep venous reflux (as a result of the thrombosis) can cause incompetence of the PV.

\section{IPV IV: IPV in Association With Isolated Deep Reflux}

This IPV is found with deep venous reflux, caused by primary valvular incompetence.

\section{IPV V: Isolated Type}

No other venous reflux is found. This type of IPV is rare. ${ }^{16,42,43}$ The question is whether the reflux in these PVs is physiologic.

\section{Diagnostic Methods}

How can we detect IPVs? Clinical examination alone is not reliable to detect IPVs, although IPVs can present as 
blowouts, and on palpation, a rather painful fascia defect can be found. ${ }^{31}$ These "clinically detected perforators" are often confused with simple ampullary dilation of a varicose segment. ${ }^{78}$ During surgical exploration, surgeons found that these clinically detected "perforators" showed often no evidence of a related IPV. ${ }^{79,80}$

IPV can be detected with continuous wave (CW) Doppler, but CW Doppler has no advantage over clinical examination. ${ }^{81}$ Compared with Duplex, CW Doppler has a low sensitivity $(29 \%)$ and low specificity $(15 \%)$ in detecting IPVs. ${ }^{27}$ Nowadays, CW Doppler is not considered a reliable method to diagnose IPV. ${ }^{27,78,81,82}$

Ascending phlebography and varicography are valuable for detecting perforator incompetence. Diagnosis of an IPV is made when contrast is seen to pass from deep to superficial system. Further radiographic features of an incompetent communicating vein are dilation, irregularity, and peripheral tortuosity. There have been several studies in which phlebography of IPV has been compared with surgery. Considering findings at surgical exploration as $100 \%$, phlebography was able to detect $65 \%^{83}$ to $90 \%{ }^{84}$ of IPV. Although many investigators consider surgical exploration as reliable, a common definition of an IPV found at surgical exploration is not available. When compared directly with full-calf exploration at surgery, ascending venography identifies approximately $80 \%$ of IPV. ${ }^{85,86}$ The addition of varicography to venography identifies $90 \%$ of IPV. ${ }^{84,85}$

Duplex ultrasound sonography has become the method of choice in detecting IPV in recent years. It is noninvasive, well tolerated, easy to perform, and cost effective. With Duplex, PVs can be visualized. The diameter can be measured, and the direction of flow can accurately be seen and described. ${ }^{14}$ One disadvantage could be that PVs that are smaller than $1 \mathrm{~mm}$ in diameter are difficult to visualize and measure flow within them, although it is not certain whether PVs of this size are clinically or hemodynamically relevant. The accuracy of Duplex for the diagnosis of IPV of the Cockett group is comparable to phlebography. ${ }^{87}$ In one prospective study, Duplex was even more effective to detect IPVs compared with surgery than phlebography was. ${ }^{83}$ A number of other studies have been performed in which preoperative Duplex investigation of IPV has been compared with intraoperative findings. Again, no reliable definition of IPV at surgical exploration is known. Good correlations between preoperative Duplex and intraoperative findings have been found. ${ }^{83,87,88}$ Philips et al. ${ }^{84}$ and Pierik et al. ${ }^{28}$ could not confirm this. Philips performed a prospective study at 93 patients with IPV and varicosis. In only $60 \%$, the findings of IPV by Duplex could be confirmed intraoperatively. The sensitivity of Duplex in this study could not be assessed because surgical exploration was only done when abnormalities were demonstrated by either Duplex or venography. Pierik et al. ${ }^{28}$ investigated 42 patients with venous ulceration and found a specificity of Duplex of $100 \%$ and a sensitivity of $79 \%$. However, they ligated any PV seen at surgical exploration, without knowing or defining whether they were incompetent.

Most phlebologists consider duplex ultrasound as the method of choice to detect IPV, despite the fact that Duplex provides only reliable anatomical information and limited functional data. A test in which topographic assessment along with functional evaluation is performed would be most welcome in order to predict treatable perforators.

\section{Role of IPVs in venous disease}

In general, it is difficult to isolate the significance of PV incompetence from the significance of coexisting venous disease. ${ }^{22,43,44}$ This is also true if we study the effects of interruption of IPV because patients operated for IPV are often operated simultaneously on the superficial venous system and we know that reflux eliminating surgery in one part of the venous system can abolish reflux in another part. ${ }^{45,46}$

\section{Hemodynamic Role of IPV}

Studies about the hemodynamic importance of IPVs in venous disease have been performed. Bjordal ${ }^{12,13}$ examined patients with primary varicosis with simultaneous pressure and flow recording. His conclusion was that in primary varicosis, IPVs have no hemodynamic significance. The number of patients was low (6 and 21), and the diagnosis of incompetence was made by clinical examination alone. Zukowski et al. ${ }^{47}$ also studied the role of IPV in 180 patients with superficial varicosis without deep venous disease. In only 70 patients, IPVs in the calf could be found. On basis of AVP after calf muscle exercise and venous refilling time, $35 \%$ of these IPVs were found to be of major hemodynamic importance and another $35 \%$ of moderate haemodynamic importance. The authors suggest to differentiate between hemodynamic important and nonimportant IPVs before treating them. McMullin et al. ${ }^{48}$ investigated the isolated hemodynamic consequences of dysfunction of the deep, superficial, and also the perforating system in 90 limbs of patients with clinical signs and symptoms of CVI in at least one limb. A definition of CVI is not given. Duplex scanning, ascending venography, and AVP were performed. Of the 90 limbs, 17 were found to 
have no abnormalities of the deep or superficial veins on duplex scanning despite severe symptoms (history of ulcer, lipodermatosclerosis, swelling, varicose veins, or active ulcers), and on ascending venography, all of these limbs showed at least two IPVs. Their conclusion was that these symptoms were due to IPV alone, and hemodynamic function test showed that there was a significant difference in these patients compared with those without any objective venous problem.

The hemodynamic effect of ligation of IPV in patients with superficial venous incompetence has also been studied. Fitridge et al. ${ }^{49}$ performed a prospective randomized trial evaluating the hemodynamic role of calf IPV. They investigated 38 limbs with uncomplicated varicose veins with both long saphenous and calf perforator incompetence but without evidence of deep vein incompetence. Saphenofemoral junction ligation, stripping of the long saphenous vein to the knee, and stab avulsions of any visible varicosities in the leg were performed. Patients were randomized to have the incompetent calf perforators ligated or left intact. Hemodynamic function was evaluated with air plethysmography preoperatively and 2 months postoperatively. No significant hemodynamic difference was demonstrated between the two groups. Their conclusion was that there is no additional hemodynamic advantage of perforator ligation in patients with uncomplicated varicose veins at follow-up at 3 months. The number of patients investigated, however, is rather low, and the follow-up period is short. Rhodes et al. ${ }^{50}$ performed subfascial endoscopic perforator vein surgery (SEPS) on 31 legs in patients with advanced CVI. Of these patients, $77 \%$ revealed deep venous reflux on preoperative Duplex scanning. In 30 legs, the superficial system was operated simultaneously (stripping, crosse-ectomy, or stabavulsion). SEPS alone was performed in one limb only. Strain-gauge plethysmography was performed preoperatively and 6 months after. To analyze the relative contribution of perforator ligation, two groups were formed: one group in which SEPS was performed with high ligation with or without saphenous stripping $(n=24)$ and one group $(n=7)$ in which SEPS was performed with avulsion of varicosities in six patients and SEPS alone in one patient. Improvement of calf muscle pump function and venous incompetence reached statistical significance in group 1 only, the group in which the superficial reflux was also operated. Clinical score and outcome, however, improved statistical significant in both groups.

The hemodynamic role of IPV in patients with deep venous incompetence has also been investigated. Deep venous incompetence can be caused by primary valvular incompetence or by thrombosis of the deep veins. Several studies showed no statistical significant hemodynamic improvement of venous function after perforator ligation in post-thrombotic legs. ${ }^{34,51-54}$ The number of patients in these studies is low. One study ${ }^{50}$ showed a significant hemodynamic improvement of SEPS in patients with primary valvular incompetence and no significant hemodynamic improvement in postthrombotic patients.

\section{IPVs and Venous Ulceration}

Venous ulceration develops whenever the calf muscle pump, necessary to maintain venous return against the force of gravity, fails. ${ }^{55}$ This calf pump failure leading to venous hypertension may occur in patients with varicose veins and in patients with deep venous incompetence. ${ }^{56}$ It is not known what the exact role of IPV is in the development of venous ulceration. The association of IPV with venous ulceration was observed in classic studies of Linton, ${ }^{7}$ Cockett and Jones, ${ }^{8}$ and Dodd and Cockett. ${ }^{57}$ Although IPVs, in combination with other venous pathology, were found frequently in patients with venous ulceration $(40 \%$ to $60 \%),{ }^{15,58,59}$ isolated perforator vein incompetence is found in less than $5 \%{ }^{58-60}$ to $8.4 \% .^{42}$ In nearly half of the patients with venous ulceration, no evidence of IPV (or other venous disease) was found within $2 \mathrm{~cm}$ of the ulcer periphery. ${ }^{42}$ All of these studies used duplex ultrasonography to detect IPV. The possible (important) influence of IPV on venous ulcers is indicated by the results of perforator surgery at patients with venous ulceration. Some studies show low recurrence rates $^{24,61}$ and shorter ulcer healing time compared with conservative care. De Palma and Kowallek ${ }^{62}$ showed in a crossover study that failure of conservative care could be reversed by intervention with sectioning of PVs. The number of patients was low (10), and in $70 \%$, stripping of the long saphenous vein was performed simultaneously. It is also known that sclerotherapy of periulcer varices and perforators can significantly improve local venous hemodynamics and speed ulcer healing. ${ }^{63}$ Unfortunately, in most of these studies, superficial venous reflux was treated before or simultaneously with ligation of IPV. It is known that ablation of superficial venous reflux alone in patients with venous ulceration shows a good ulcer healing $(80 \%$ to $90 \%$ after 18 and 42 months, respectively), ${ }^{60,64}$ and therefore, the effect of perforator ligation is difficult to interpret. The study of Proebstle et al. ${ }^{54}$ shows the importance of incompetence of the superficial venous system in venous ulceration: They performed SEPS on 16 patients with venous ulceration. They selected patients that had already received stripping or ligation of incompetent superficial veins. In their series, only $56 \%$ of the ulcers healed after 56 days, which is lower than the usual healing rates with 
SEPS ( $88 \%$ after 1 year ${ }^{61}$ and $92 \%$ after 3 months $\left.{ }^{65}\right)$. It must be noted, however, that they only treated those IPVs that had been detected preoperatively by Duplex or phleboradiography instead of treating all visible PVs (competent or incompetent), as is the normal procedure in SEPS. The presence of deep venous incompetence was found to be a useful indicator of ulcer recurrence. ${ }^{66}$ Unfortunately, the etiology of this incompetence (posthrombotic or primary valvular incompetence) was not documented in this study. Several studies show that healing is slower and/or ulcer recurrence is higher in legs with postthrombotic deep venous incompetence compared with legs without deep venous incompetence, ${ }^{61,67,68}$ although clinical improvement can be significant even in this group. ${ }^{50} \mathrm{In}$ legs with deep venous incompetence caused by primary valvular incompetence, there is a significant improvement of ulcer healing and recurrence rate after ligation of IPV. ${ }^{50,61}$

\section{IPVs and Superficial Varicosis}

As stated before, IPV I can be a cause of varicosis, and IPV II can be the result of varicosis. There are several studies on the presence of IPV in patients with recurrent varicosis. Most studies show a high prevalence of IPV in patients with recurrent varicose veins after surgery, ${ }^{6-74}$ especially incompetent thigh PVs. ${ }^{37,75,76,77}$ Although there seems to be an association between IPV and recurrent varicose veins, it is now essential to establish whether this is a causative link. ${ }^{73}$

\section{Therapy}

Whether perforators should be dealt with at all remains a controversial question. Several authors are rather sceptical about the need for treatment. ${ }^{10,22,89}$ They consider PVs in the leg as a part of a compensatory mechanism contributing to venous return. ${ }^{39}$ It has been described that IPVs can be found in a greater number after correction of the raised superficial venous pressure,$^{69-74}$ probably as a consequence of the new hemodynamic and pathophysiologic scene. ${ }^{39}$ Some authors have shown that selective ligation of IPVs, in absence of deep venous reflux, does not improve venous hemodynamics. ${ }^{49,50}$ Most studies on treatment of IPV treat the superficial system as well, ${ }^{90}$ and because we know that correction of superficial reflux leads to correction of pathological outward flow in PVs in most cases $(80 \%), 30,31,64,91$ it is almost impossible to judge the effect of ligation of IPV alone. According to Stuart et al., ${ }^{30}$ much of the controversy about the appropriateness of perforator ligation could be caused by differences in case mix and selection between series. Several authors proposed to differentiate between clinical types of IPV when selecting patients for perforator therapy. ${ }^{30-33}$

Referring to the former classification (Table 1), we can try to formulate a therapeutic strategy.

\section{IPV I}

All authors agree that this type of IPV needs to be treated in order to prevent recurrence of the superficial venous insufficiency distal of the IPV. ${ }^{92}$

\section{IPV IIa}

Correction of proximal superficial reflux is considered to be the first therapeutic step and is of great importance. The venous refill time recovers dramatically, ${ }^{90}$ and the IPVs become competent in most cases $(80 \%),{ }^{30,91,93}$ with the best effect on the PVs above the knee. ${ }^{91}$ Correction of reflux in the GSV has shown to reduce the diameter of lower leg perforators ${ }^{30}$ until 6 months after operation. ${ }^{94}$ It is not known whether the remaining $20 \%$ of the IPVs have any hemodynamic importance. $^{33,39}$

\section{IPV IIb}

Two studies ${ }^{45,46}$ showed that surgical eradication of superficial venous reflux (GSV) can correct reflux in the deep veins, a finding confirmed by others, ${ }^{94}$ and thus, it is worthwhile to correct the saphenous reflux, even in patients with deep venous reflux.

If the deep venous reflux does not disappear after superficial correction, it is unknown whether this IPV should be treated. However, the IPV could still be (functional) relevant, and thus, most authors tend to treat these IPVs, ${ }^{30,33}$ especially when skin changes are present. $^{31}$

\section{IPV IIIa}

All authors agree that this type of IPV should not be treated. This IPV function as an "escape" possibility. Treatment would deteriorate the venous pathology.

\section{IPV IIIb (Thrombosis Recanalized)}

The benefit of treatment of IPV in patients with postthrombotic deep venous incompetence remains unproven by controlled data. ${ }^{32,33,41,67}$

\section{IPV IV}

In patients with IPV and primary valvular incompetence, it seems to be appropriate to treat these IPV. ${ }^{50,61}$ 


\section{IPV V}

Because we do not know whether these IPVs are functional, it is unknown whether this type of IPV should be treated. According to some authors, there are special indications in which treatment of IPV could be of benefit: patients who have highly symptomatic CVI (pain), ${ }^{79}$ patients who have threat of ulceration or have recurrent refractory ulceration, ${ }^{95}$ patients with elective localization of trophic lesions over IPVs, and cases of secondary skin changes with CVI Widmer II of III. ${ }^{31}$ Treatment of IPV has also been recommended in nonsaphenous varices. ${ }^{95}$

\section{Method of Treatment of IPV}

Whenever the decision has been made that treatment of IPV is necessary, there are different techniques possible.

\section{Surgery}

Linton ${ }^{7}$ was the first to suggest and perform ligation of IPVs. Before the ligation of the PVs, high ligation of incompetence GSV and short saphenous vein should be performed. His perforator operation, called Linton's procedure, required a long skin incision, and wound complications were frequently noted. Is it now widely accepted that open perforator ligation, like the Linton's procedure, is associated with an unacceptable level of morbidity, and therefore, these procedures have largely been abandoned. ${ }^{30,89,104}$

Queral and Criado96 performed a "purse-string" permanent suture technique for IPVs. The procedure is easy to perform and has very encouraging early results. The recurrence rate of venous ulceration is low. Queral and Criado stated that this technique is valuable in the treatment of patients with venous ulceration associated with incompetent calf perforators.

\section{SEPS}

In recent years, SEPS has rapidly developed at a minimally invasive technique to interrupt PVs. ${ }^{97}$ The technique is as follows: Through a small incision in the upper calf, away from the skin with lipodermatosclerosis or ulceration, an endoscope is introduced between the fascia and the underlying muscle. The instrument is advanced down to intercept all visible PVs, which may be clipped, treated with diathermy, or simply cut. ${ }^{89}$ Edwards ${ }^{98}$ was the first to introduce the "phlebotome" for blind sectioning of leg perforators, using only a small incision at the upper part of the leg, outside areas affected by lipodermatosclerosis. In 1985, Hauer ${ }^{99}$ used a mediastinoscope or rigid proctoscope to insert under the medial superficial leg aponeurosis. The technique has been refined since then with the introduction of endoscopy, insufflation of $\mathrm{CO}_{2}$ (two-channel technique), external retraction technique, ${ }^{100}$ and the video endoscopy. ${ }^{101}$ Advantages of SEPS are that compared with the classic perforator surgery techniques, SEPS is associated with significantly less morbidity, smaller scars, and a shorter hospital stay. ${ }^{24,102-104}$ Complications of SEPS are low. Wound complications occur in $4 \%$ to $6 \% .{ }^{105}$ Deep vein thrombosis occurs occasionally. ${ }^{103}$ Pain $(1.5 \%)$ and paresthesia $(6 \%)$ can also occur, especially when using the electrocautery in the subfascial space. ${ }^{106}$ Case reports of iatrogenic leg ulcer ${ }^{107}$ and arteriovenous fistula ${ }^{108}$ have been reported. A disadvantage of SEPS is that it is more cost-effective in healing venous ulcers compared with compression bandaging. ${ }^{109}$ SEPS is mostly performed in patients with venous ulceration (with active or healed venous ulceration C5 and C6). It is usually performed in combination with ablation of the superficial venous reflux and is considered successful in the treatment of venous leg ulceration. Several short- and mid-term clinical series have validated high healing rates $(84 \%$ to $100 \%)$ and low recurrence rates (recurrences at 2 years, $0 \%$ to $22 \%$ )..$^{24,54,61,65,110}$ Compared with the results of conservative treatment of venous leg ulceration (recurrence rate of $29 \%{ }^{111}$ to $\left.66 \%{ }^{112}\right)$, this is clinically highly relevant. Reliable long-term results of SEPS compared with (modified) Linton procedure are not available, although they seem to be comparable. ${ }^{24}$

In patients with venous ulceration and deep venous reflux, the effect of surgical treatment of IPV over optimal medical management needs to be further investigated. ${ }^{24,61} \mathrm{~A}$ significant higher ulcer recurrence rate after SEPS is found in the postthrombotic group. ${ }^{52,61}$ However, the clinical benefit of SEPS was evident in this group even in patients with persistent or recurrent ulcers. ${ }^{61}$ Even in patients with postthrombotic syndrome, SEPS showed a reduction in diseaserelated symptoms (pain and oedema), improved hemodynamics in almost $60 \%$, and facilitated healing of long-lasting ulcers. ${ }^{54}$ Despite this clinical improvement, the long-term effects of SEPS in patients with venous ulceration and deep venous incompetence are not clear: Sybrandy et al. ${ }^{24}$ found a high number of newly developed PVs 4 years after performing SEPS. This finding was significantly influenced by the presence of deep venous incompetence. Unfortunately, there is no specification about the origin of this deep venous incompetence (primary valve incompetence or post-thrombotic). A possible explanation for this phenomenon could be that persistent high venous pressure in the calf causes new IPVs to develop. ${ }^{24}$ The role of SEPS in venous insufficiency with only skin symptoms (no ulceration) remains controversial.

Encouraging results have been published using SEPS (combined with phlebectomy and partial of complete stripping of GSV) in the treatment of recurrent 
varicose veins and CVI. ${ }^{105}$ More prospective, randomized trials are needed to evaluate the effect of SEPS on primary varicosis and CVI. ${ }^{113}$

Ultrasound-guided percutaneous coil embolisation of IPV has been investigated but proved to be ineffective for treatment of venous ulcers and recurrent varicosities. $^{114}$

\section{Sclerotherapy}

No consensus has yet been reached about the role of sclerotherapy of IPV. ${ }^{115-117}$ There are only a few good studies on the effect of sclerotherapy for IPVs of the lower legs (Table 2). Fegan ${ }^{37}$ described in 1963 the technique of injection into superficial veins adjacent to the IPV with the leg raised and applying immediate compression afterward. He used 0.5 -ml sodium tetradecylsulfate (STDS) 3\%. No conclusions from this study can be drawn because detection of IPV was performed by clinical examination alone.

In a comprehensive study comparing surgery and sclerotherapy, Hobbs ${ }^{93}$ concluded that the best primary treatment for IPV in the lower part of the legs was injection-compression therapy. His article shows that after a follow-up period of 6 years, only $20 \%$ of the IPV treated with sclerocompression was cured. Hobbs also used 0.5- to $0.75-\mathrm{ml}$ STDS 3\%. However, in his article, Hobbs was not convinced that the injection was always made at the side of the PV and certainly not directly into it. He used the term "points of control" rather than "perforators" and stated that "it is hoped that all IPVs are included."

There are two prospective studies on ultrasoundguided sclerotherapy (USGS) for IPVs: Thibault and Lewis ${ }^{69}$ performed an open prospective study on 36 patients. He treated them with 0.5 - to 1 -ml STDS $3 \%$. Before treatment, high-risk sites such as calf PVs were scanned with pulsed Doppler for arterial signs. In $15 \%$, he needed more than one injection. Compression was applied for 4 weeks. Follow-up at 6 months revealed $73 \%$ to $100 \%$ success. The best results were obtained with injection of incompetent gastrocnemius PVs. Incompetent thigh PVs were found difficult to treat if they were small and located more than $2.5 \mathrm{~cm}$ beneath the skin. Thibault and Lewis concluded that there is need for further refinement of the technically difficult procedure and need for development of a needle guide probe attachment to aid precise localisation of the needle tip at a depth of 0.5 to $3 \mathrm{~cm}$. Complications like deep vein thrombosis, pulmonary embolism, or intra-arterial injection were not seen.

In another open prospective study by Schadeck, ${ }^{118}$ STDS $3 \%$ was used to treat IPVs in 51 patients. Correction of the superficial reflux was first performed. During injection much attention was paid to avoid entering the PVs because of possible intra-

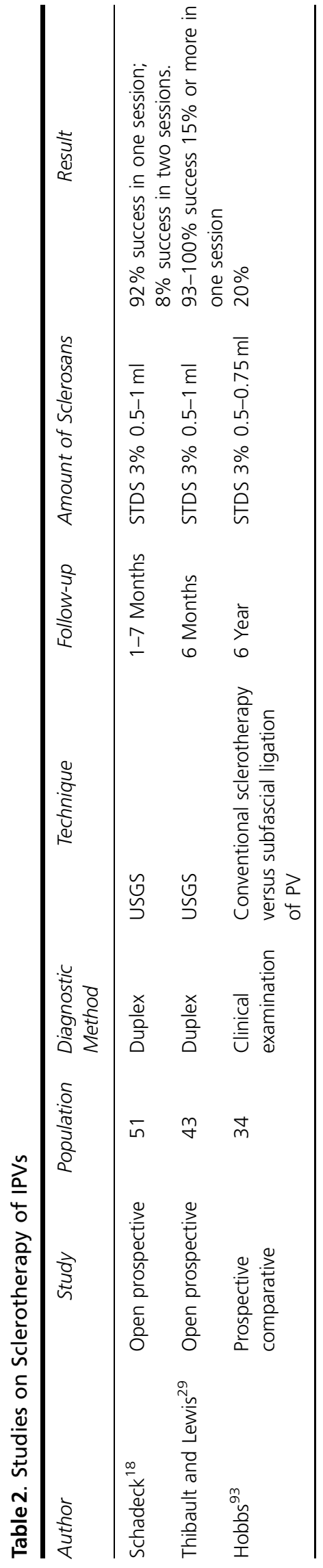


arterial injection. Follow-up at 1 to 7 months revealed $92 \%$ success in one session and another $8 \%$ in two sessions. No compression was applied. Complications such as redness, pain, and induration were seen in $40 \%$. No intra-arterial injection, deep vein thrombosis, or nerval damage occurred.

Guex $^{95}$ stated in his article on USGS for PVs that in his experience, occlusion of IPV with USGS is obtained in about $90 \%$ of the cases with three or less sessions. Veins with a diameter of more than $8 \mathrm{~mm}$ are more likely to be resistant to sclerotherapy. In his opinion, future studies should include preoperative and postoperative diameter and reflux duration, plethysmographic evaluation of therapy, and duplex-visible sclerosis of the veins.

Despite this lack of consensus, several authors treat IPV with sclerotherapy. ${ }^{36}$ IPV of Hunter ${ }^{20,117}$ and IPV of Boyd ${ }^{117}$ seem to react very well to sclerotherapy. The results of sclerotherapy of ankle perforators are less convincing, ${ }^{117}$ although good results have been claimed in patients with venous ulcers. ${ }^{119}$

Complications of sclerotherapy of IPV are equal to complications that occur with sclerotherapy of varicose veins: hyperpigmentation, phlebitis, necrosis, allergy, and intra-arterial injection. ${ }^{120}$ Hyperpigmentation and phlebitis occur regularly, and the other complications are rare ${ }^{121}$ despite the fact that almost every PV runs with an artery.

It is clear that treatment of IPVs by means of sclerotherapy needs to be investigated more in the future. Regarding long-term results, no controlled study and no data on recurrence rate are available. ${ }^{95}$ For instance, in his clinical review on sclerotherapy of varicose veins, Green ${ }^{122}$ criticized the short follow-up periods of studies on sclerotherapy of IPV. In his opinion, 1-year follow-up is necessary to claim success. USGS seems to be most promising. In a meeting report on REVAS (recurrent varices after surgery), ${ }^{123}$ it is stated that the technique of USGS of PVs is worth further evaluation.

\section{Discussion}

Despite the fact that PVs have been known for a long time, much knowledge about these veins is still lacking. For instance, there is a lot of confusion about the nomenclature of PV. A recent consensus document suggests a new anatomical classification to locate PVs. We would recommend every phlebologist to use this classification. Various authors have tried to make a clinical classification of IPVs. Summarizing these clinical classifications, a proposal is done to divide IPVs in five clinical types (Table 1). Hopefully this clinical classification will contribute to a perforator classification analogous to or even integrated in the CEAP classification.
We know that PVs direct blood flow from superficial to deep veins (inward flow), and we know their valves are helpful in this procedure. The smaller PVs (less than $1 \mathrm{~mm}$ in diameter) are valveless, and they are considered of little or no hemodynamic importance. It is also known that blood can flow from the deep to the superficial system as well (outward flow or reflux). This bidirectional flow can occur in patients with venous disease but also in healthy persons. It is not understood what the meaning of this reflux in healthy persons is. Do we have to consider this as a physiologic phenomenon, or is this reflux the beginning of venous disease? It would be very interesting to follow over time these healthy persons with reflux in their PVs to see whether they develop venous symptoms.

There is no good definition of IPVs. The mostly used criterion of incompetence is reflux of more than 0.5 seconds, best detected by means of Duplex ultrasonography. Most phlebologists agree on the fact that if a PV shows no reflux, it has no hemodynamic significance. Although it has been shown that IPVs have bigger diameters than competent ones, this is not regarded as a good criterion to define incompetence. We need more sensitive and specific measure techniques in order to discriminate between physiologic and pathologic reflux, and we certainly need more criteria to define and grade incompetence of PVs. We probably need a functional test as well, and maybe we ought to take clinical findings into account to define incompetence.

What exactly is the role of IPV in venous disease? Results of hemodynamic studies are conflicting but show that IPVs can be of hemodynamic significance. In general, it is difficult to isolate the significance of PV incompetence from the significance of coexisting venous disease. There are no good studies that investigate solely the role of IPVs in venous disease. This is unfortunate because we know for instance that in patients with superficial reflux and IPV, correction of this superficial reflux causes most of the IPVs to become competent. Thus, whenever we want to study the influence of IPVs, any coexisting superficial reflux should be dealt with beforehand.

In the development of venous ulceration, there could be a role for IPVs because epidemiologic studies show that IPVs are found in $60 \%$ of patients with venous ulceration. It is difficult to interpret the significance of IPVs in venous ulceration from the results of SEPS because not only are most surgeons dealing with superficial reflux at the same time as they perform SEPS but also all PVs seen during the operation are ligated, whether they are incompetent or not. After SEPS procedures, IPVs can persist, or even new IPVs can develop. SEPS is performed successfully in patients with active or healed venous 
ulceration (C5, C6) but remains controversial in patients with only skin symptoms.

Primary insufficiency of a PV can cause varicosis. A good example is primary incompetence of the Hunterian perforator as a common cause of medial thigh varicosis in patients with a competent saphenofemoral junction. There is a high prevalence of IPVs in patients with recurrent varicose veins, and we know that IPVs can be a cause of recurrent varicosis. A good example is the IPV of Boyd, which can cause recurrent varicosis of the GSV of the lower leg after a short strip of the GSV, although some surgeons tend to treat the IPV of Boyd during a short strip procedure.

Regarding therapy of IPV, it is important to take the clinical types into account: IPV I (primary type) and IPV IV (IPV with isolated deep venous reflux caused by primary valvular incompetence) can be dealt with. In case of IPV II (IPV secondary to a varicose vein, with or without deep venous reflux), it is necessary to treat the superficial reflux first. Whether the remaining IPV should be dealt with is unknown. IPV IIIa (IPV with thrombosis, not recanalized) should not be treated. No controlled data are available for the justification of treatment of IPV IIIb. IPV V (isolated type) could be physiologic, and thus, treatment is most probably inappropriate unless clear clinical signs are present.

There are two important treatment options for IPV: surgery and sclerotherapy. SEPS has become a popular surgical technique to treat IPVs. SEPS (together with ablation of superficial reflux) seems to be appropriate in patients with venous ulceration and advanced CVI, although level 1 evidence is still lacking. Short-term results show that SEPS is certainly preferable to the classic Linton's procedure. In patients with deep venous incompetence, hemodynamic improvement with SEPS is seen in only the patients with primary valvular incompetence and not in patients with postthrombotic syndrome, although clinical symptoms can improve in these patients as well. The development of new IPVs 4 years after SEPS is worrying, and the implications of this finding need to be investigated more thoroughly.

The effect of sclerotherapy on IPV has been investigated by several authors. It certainly causes less complications then any surgical therapy. Until now, no controlled data and certainly no reliable long-term results are available. Nevertheless, sclerotherapy of IPVs, especially USGS, is promising and needs further evaluation.

\section{References}

1. Von Loder JC. Anatomische tafeln. Weimar, 1803.

2. Hage RW. Venae communicantes van het onderbeen. Thesis, 1982.
3. Gay J. On varicose disease of the lower extremities. The Lettsomian Lectures, 1867.

4. Bordeu M. Recherches sur les maladies chronique. Paris: Presse Medicale, 1775.

5. Briquet P. Trunk, tributaries, tertiaries and telangiectases. Paris: These de Paris, 1824.

6. Turner-Warwick W. The rational treatment of varicose veins and varicocele. London: Faber \& Faber, 1931.

7. Linton RR. The communicating veins of the lower leg and the operative technique for their ligation. Ann Surg 1938;107:582-93.

8. Cockett FB, Jones DE. The ankle blow-out syndrome: a new approach to the varicose ulcer problem. Lancet 1953;1:17-23.

9. van Limborgh J. L'anatomie du systeme veineux de l'extremite inferieure en relatio avec la pathologie variqueuse. Folia Angiologica 1961;8:240.

10. Perrin NA. Les Perforantes jambieres. J Mal Vasc 1999;24:19-24.

11. Almen T, Nylander G. Serial phlebography of the normal lower leg during muscular contraction and relaxation. Acta Radiol 1962;264-72.

12. Bjordal R. Simultaneous pressure and flow recordings in varicose veins of the lower extremity. Acta Chir Scand 1970;136:309-17.

13. Bjordal R. Circulation patterns in incompetent perforating veins in the calf and in the saphenous system in primary varicose veins. Acta Chir Scand 1972;138:251-61.

14. Sarin S, Scur JH, Smith C. Medial calf perforators in venous disease: the significance of outward flow. J Vasc Surg 1992;16:40-6.

15. Labropoulos N, Mansour MA, Kang SS, et al. New insights into perforator vein incompetence. Eur J Vasc Endovasc Surg 1999;18:228-34.

16. Stuart WP, Adam DJ, Állan PL, et al. The relationship between number, competence, and diameter of medial calf perforating veins and the clinical status in healthy subjects and patients with lowerlimb venous disease. J Vasc Surg 20001981 49-59;32:138-43.

17. Van Limborgh J, Hage RW. Anatomic features of those perforating veins of the leg which frequently of infrequently become incompetent. In: May R, Portsch H, Staubesand J, eds. Perforating Veins. München: Urban and Schwarzenberg, 1981.

18. Caggiati A, Bergan JJ, Gloviczki P, et al. Nomenclature of the veins of the lower limbs: an international interdisciplinary consensus statement. J Vasc Surg 2002;36:416-22.

19. Goldman MP, Weiss RA, Bergan JJ. Diagnoses and treatment of varicose veins: a review. J Am Acad Dermatol 1994;31:393-413.

20. Lawday-Mussot S. La veine perforante du canal de Hunter son incidence dans la pathologie variquese et son traitement. Phlebologie 1991;44:697-731.

21. Wittens CHA, Toonder IM, Korten E. Do diameters of perforating veins correlate with incompetence: the 2 nd mayo vascular symposium, Rochester, MN, 2000;128-129.

22. Danielsson G, Eklof B, Kistner RL. What is the role of incompetent perforator veins in chronic venous disease. JP 2001;1:67-71.

23. Delis KT, Husmann M, Kalodiki E, et al. In situ hemodynamics of perforating veins in chronic venous insufficiency. J Vasc Surg 2001;33:773-82.

24. Sybrandy JEM, Van Gent WB, Pierk EGJM, Witters CHA. Endoscopic versus open subfascial division of incompetent perforating veins in the treatment of venous leg ulceration: longterm follow-up. J Vasc Surg 2001;33:1028-32.

25. Laroche JP, Guex JJ, Coupé M. Exploration par echo-doppler des perforantes jambières. Phlebologie 1997;50:669-77.

26. Sandri JL, Barros FS, Pontes S, et al. Diameter-reflux relationship in perforating veins of patients with varicose veins. J Vasc Surg 1999;30:867-75.

27. Schultheiss R, Billeter M, Bollinger A, et al. Comparison between clinical examination, CW Doppler ultrasound and colour-duplex sonography in the diagnosis of incompetent perforating veins. Eur J Vasc Endovasc Surg 1997;13:122-6.

28. Pierik EG, Toonder IM, van Urk H, et al. Validation of duplex ultra sonography in detecting competent and incompetent perforating veins in patients with venous ulceration of the lower leg. J Vasc Surg 1997;26:49-52.

29. Thibault PK, Lewis WA. Recurrent varicose veins: I: evaluation utilizing duplex venous imaging. J Dermatol Surg Oncol 1992;18:618-24. 
30. Stuart WP, Adam DJ, Allan PL, et al. Saphenous surgery does not correct perforator incompetence in the presence of deep venous reflux. J Vasc Surg 1998;28:834-8.

31. Clerici Th, Sege D. Perforans-sanierung Zentralbl chir. 1999;124:525-9.

32. Sahary M, Scurr JH. Minimally invasive surgery for perforator vein incompetence. Cardiovasc Surg 1996;4:701-5.

33. Rabe E. Beurteilung der insuffizienten venae perforantes mit der farbkodierten. Duplexsonographie Phlebologie 1994;23:146-8.

34. Burnand KG, O’Donnell T, Lea Thomas M, et al. The relative importance of incompetent communicating veins in the production of varicose veins and venous ulcers. Surgery 1977;82:9-14.

35. Hach W. Die rezirkulationskreise der primären varikose. Phlebologie 1991;20:81-4.

36. Bergan JJ. Perforating veins. In: Bergan JJ, Goldman MP, eds. St. Louis: Varicose Veins and Teleangiectasias: Diagnosis and Treatment. Quality Medical Publishing, 1993.

37. Fegan WG. Continuous compression technique of injections varicose veins. Lancet 1963;2:109-12.

38. Trendelenbrug F. Uber die unterbinding der vena saphena magna bei unterschenkel varizen. Bruns Beitr Zur Klin Chir 1891;7: 195-210.

39. Rutherford EE, Kianifard B, Cook SJ, Holdstock JM, Whiteley MS. Incompetent perforating veins are associated with recurrent varicose veins. Eur J Vasc Endovasc Surg 2001;21:458-460.

40. Stuart WP, Lee AJ, Allan PL. Most incompetent calf perforating veins are found in association with superficial venous reflux. J Vasc Surg 2001;34:774-8.

41. Almgren B, Eriksson L. Primary deep venous incompetence in limbs with varicose veins. Acta Chir Scand 1989;155:455-60.

42. Hanrahan LM, Araki CT, Rodriguez AA, et al. Distribution of valvular incompetence in patients with venous stasis ulceration. J Vasc Surg 1991;13:805-12.

43. Labropoulos N, Delis K, Nicolaides AN, et al. The role of the distribution and anatomic extent of reflux in the development of signs and symptoms in chronic venous insufficiency. J Vasc Surg 1996;23:504-10.

44. Moore DJ, Himmel PD, Summer DS. Distribution of venous valvular incompetence in patients with the postphlebitic syndrome. J Vasc Surg 1986;3:49-57.

45. Walsh JC, Bergan JJ, Beeman S, et al. Femoral venous reflux abolished by greater saphenous vein stripping. Ann Vasc Surg 1994;8:566-70.

46. Sales CM, Bilof ML, Petrillo KA, et al. Correction of lower extremity deep venous in competency by ablation of superficial venous reflux. Ann Vasc Surg 1996;10:186-9.

47. Zukowski AJ, Nicolaides AN, Szendro G, et al. Haemodynamic significance of incompetent calf perforating veins. $\mathrm{Br} \mathrm{J}$ Surg 1991;78:625-9.

48. McMullin GM, Scott HJ, Coleridge Smith PD, Scurr JH. A reassessment of the role of perforating veins in chronic venous insufficiency. Phlebology 1990;5:85-94.

49. Fitridge RA, Dunlop C, Raptis S, et al. A prospective randomized trail evaluating the haemodynamic role of incompetent calf perforating veins. Aust N Z J Surg 1999;69:214-6.

50. Rhodes JM, Gloviczki P, Canton L, et al. Endoscopic perforator vein division with ablation of superficial reflux improves venous hemodynamics. J Vasc Surg 1998;28:839-47.

51. Stacey MC, Burnand KG, Layer GT, et al. Calf pump function in patients with healed venous ulcers is not improved by surgery to the communicating veins or by elastic stockings. Br J Surg 1988;75:436-9.

52. Rhodes JM, Gloviczki P, Canton IG, et al. Factors affecting clinical outcome following endoscopic perforating vein ablation. Am J Surg 1998;176:162-7.

53. Akesson H, Brudin L, Cwikiel W, et al. Does the correction of insufficient superficial and perforating veins improve venous function in patients with deep venous insufficiency? Phlebology 1990;5:113-23.

54. Proebstle TM, Weisel G, Paepcke U, et al. Light reflection rheography and clinical course of patients with advanced venous disease before and after endoscopic subfascial division of perforating veins. Dermatol Surg 1998;24:771-6.
55. Burnand. Aetiology of venous ulceration. Br J Surg 1990;77:483-4.

56. De Palma R. Do primary varicose veins lead to ulceration? Vasc Surg 1996;30:1-3.

57. Dodd H, Cockett FR eds. The Management of Venous Ulcers. In: The Pathology and Surgery of the Veins of the Lower Limbs. New York: Churchill-Livingstone, 1976:269-96.

58. Yamaki T, Nozaki M, Sasaki K. Color duplex ultrasound in the assessment of primary venous leg ulceration. Dermatol Surg 1998;24:1124-8.

59. Labropoulos N, Leon N, Geroulakos G. Venous hemodynamic abnormalities in patients with leg ulceration. Am J Surg 1995;169: $572-4$.

60. Darke SG, Penfold C. Venous ulceration and saphenous ligation. Eur J Vasc Surg 1992;6:4-9.

61. Gloviczki P, Bergan JJ, Rhodes JM, et al. Mid-term results of endoscopic perforator vein interruption for chronic venous insufficiency: lessons learned from the North American subfascial endoscopic perforator surgery registry. J Vasc Surg 1999;29: 489-502.

62. De Palma RG, Kowallek DL. Venous ulceration: a crossover study from non-operative to operative treatment. J Vasc Surg 1996;24:788-92.

63. Queral LA, Francisco JC. The role of sclerotherapy as an adjunct to Unna's boot for treating venous ulcers: a prospective study. J Vasc Surg 1990;11:572-5.

64. Bello M, Scriven M, Hartshorne T, et al. Role of superficial venous surgery in the treatment of venous ulceration. $\mathrm{Br} J$ Surg 1999;86:755-9.

65. Wolters U, Schmitz-Rixen T. Die behandlung insuffizienter perforans venen bei ulcus cruris venosum durch endoskopische dissection. Phlebology 1997;26:92-4.

66. Bradbury AW, Stonebridge PA, Callam MJ, et al. Foot volume try and duplex ultrasonography after saphenous and subfascial perforating vein ligation for recurrent venous ulceration. $\mathrm{Br}$ Surg 1993;80:845-8.

67. Warburg FE, Danielsen L, Madsen SM, et al. Vein surgery with or without skin grafting versus conservative treatment for leg ulcers: a randomised prospective study. Acta Derm Venereol 1994;74:307-9.

68. Burnand K, O'Donell T, Lea Thomas M, Browse NL. Relation between postphlebitic changes in the deep veins and results of surgical treatment of venous ulcers. Lancet 1976;1:936-8.

69. Thibault PK, Lewis WA. Recurrent varicose veins: II: injection of incompetent perforating veins using ultrasound guidance. J Dermatol Surg Oncol 1992;18:895-900.

70. Labropoulos N, Touloupakis E, Giannoukas AD, et al. Recurrent varicose veins: investigation of the pattern and extent of reflux with colour flow duplex scanning. Surgery 1996;119:406-9.

71. Jiang P, Van Rij AM, Christie R, et al. Recurrent varicose veins: patterns of reflux and clinical severity. Cardiovasc Surg 1999;7:332-9.

72. Farrah J, Shami SK. Patterns of incompetence in patients with recurrent varicose veins: a Duplex ultrasound study. Phlebology 2001;16:34-7.

73. Rutherford EE, Kianifard B, Cook SJ, et al. Incompetent perforating veins are associated with recurrent varicose veins. Eur J Vasc Endovasc Surg 2001;21:458-60.

74. Englund R. Duplex scanning for recurrent varicose veins. Aust N Z J Surg 1996;66:618-20.

75. Juhan C, Haupet S, Miltgen G, et al. Recurrent varicose veins. Phlebology 1990;5:201-11.

76. Stonebridge PA, Chalmers N. Recurrent varicose veins: a varicographic analysis leading to a new practical classification. Br J Surg 1998;82:60-2.

77. Loveday EJ, Lea Thomas M. The distribution of recurrent varicose veins: a phlebographic study. Clin Radiol 1991;43:47-51.

78. Pfyffer M. Präoperatieve abklärung der primären varikose. Schweiz Med Wochenschrift 1998;128:1772-80.

79. Ramelet AA, Monti M. Phlebology, the guide. Amsterdam: Elsevier, 1999:59-75.

80. Reid RG, Rothnie NG. Treatment of varicose veins by compression sclerotherapy. Br J Surg 1968;55:889-95.

81. O'Donell TF, Burnand KG, Clemenson G. Doppler examination vs clinical and phlebographic detection of the location of 
incompetent perforating veins: a prospective study. Arch Surg 1997;112:31-5.

82. Coleridge-Smith PD. Investigation of venous disease. Phlebology 2001;16:6-11.

83. Stiegler H, Rotter G, Standl R, et al. Wertigkeit der Farb-DuplexSonographie in der diagnose insuffizienter VV-perforantes VASA. Band 23; Heft, 1994;2:110-3.

84. Philips GW, Paige J, Molan MP. A comparison of colour duplex ultrasound with venography and varicography in the assessment of varicose veins. Clin Radiol 1995;50:20-5.

85. Lea Thomas $M$, Bowles JN. Incompetent perforating veins. comparison of varicography and ascending phlebography. Radiology 1985;154:619-23.

86. Lea Thomas M, McAllister V, Rose DH, et al. A simplified technique of phlebography for the localisation of incompetent perforating veins of the legs. Clin Radiol 1972;23:486-91.

87. Meyer T, Cavalerro A, Lang W. Duplex ultrasonography in the diagnosis of incompetent Cockett veins. Eur J Ultrasound 2000;11:175-80.

88. Hanrahan LM, Araki CT, Fisher JB, et al. Evaluation of the perforating veins of the lower extremity using high resolution duplex imaging. J Cardiovasc Surg 1991;32:87-97.

89. Ruckley CV, Makhdoomi KR. The venous perforator. Br J Surg 1996;83:1492-3.

90. Recek C. Venose hamodynamik in den beinen bei gesunden und bei primarer varikose. Phlebologie 2001;30:107-14.

91. Campbell WA, West A. Duplex ultrasound audit of operative treatment of varicose veins. In: Negus D, Jantet G, eds. Phlebology '95. Springer, 1995:407-9.

92. Fratila A, Rabe E. The differentiated surgical treatment of primary varicosis. Semin Dermatol 1993;2:102-16.

93. Hobbs JT. Surgery and sclerotherapy in the treatment of varicose veins: a random trial. Arch Surg 1974;109:793-6.

94. Recek C, Karisch E, Gruber J. Veränderungen der perforans venen und tiefen unterschenkelvenen nach beseitigung des saphenarefluxes. Phlebologie 2000;29:37-40.

95. Guex JJ. Ultrasound guided sclerotherapy (USGS) for perforating veins (PV). Hawaii Med J 2000;59:261-2.

96. Queral LA, Criado FJ. Mini-incisional ligation of incompetent perforating veins of the leg. J Vasc Surg 1997;25:437-41.

97. Gloviczki P. Surgical treatment of the superficial and perforating veins. Phlebology 2000;15:131-6.

98. Edwards JM. Shearing operation for incompetent perforating veins. Br J Surg 1976;63:885-6.

99. Hauer G. Endoscopic subfascial division of perforating veins: preliminary report (in German). VASA 1985;14:59-61.

100. Duff CA, Fischer RH, Linde N. Externe retraction-technik (ERT) verbessert den endoskopieraum bei der endoscopischen subfaszialen diszidion der perforans venen. Phlebologie 1999;28:132-4.

101. Sattler G, Hagedorn M. Endoscopic venous surgery in postphlebitic syndrome. Wien Med Wochenschr 1994;144:260-1.

102. Stuart WP, Adam DJ, Bradbury AW, et al. Subfascial endoscopic perforator surgery is associated with significantly less morbidity and shorter hospital stay than open operation (Linton's procedure). Br J Surg 1997;84:1364-5.

103. Lacroix H, Smeets A, Nevelsteen A, et al. Classic versus endoscopic perforating vein surgery: a retrospective study. Acta Chirg Belg 1998;98:71-5.

\section{Commentary}

In this meticulously researched and carefully crafted article, the authors probe the relationship of PVs to venous abnormalities that faces phlebologists on a daily basis. Of particular importance is their attempt to determine the role of IPVs in the production of venous disease as well as formulating both a rationale for therapy and an analysis of currently employed
104. Pierik EG, Van Urk H, Hop WC, et al. Endoscopic versus open subfascial division of incompetent perforating veins in the treatment of venous leg ulceration: a randomized trial. J Vasc Surg 1997;26:1049-54.

105. Rechner J, Riegler F-M, Ebner S, et al. Ergebnisse nach endoskopischer subfascialen insufflations-dissektion der perforans venen (ESIDP). Phlebologie 2001;30:21-5.

106. Whiteley MS, Smith JJ, Galland RB. Tibial never damage during subfascial endoscopic perforator vein surgery. $\mathrm{Br} \mathrm{J}$ Surg 1997;84:512.

107. Huang A, McWhinnie DL. Iatrogenic leg ulcer after subfascial endoscopic perforator surgery (SEPS). Phlebology 1999;14: $167-8$.

108. Fölsch C, Rauber K, Langer C. Arterio-venöse fistel nach endoskopischer dissektion der venae perforantes des unterschenkels mit dem neodym: YAG laser bei chronischen venosum stauungssyndrom. VASA 1998;27:43-5.

109. Huang A, Edwards N, McWhinnie DL. Subfascial endoscopic perforator surgery is more cost-effective than compression bandaging for healed venous ulcers. Phlebology 2001;16:76-9.

110. Nelzen O. Prospective study of safety, patient satisfaction and leg ulcer healing following saphenous and subfascial endoscopic perforator surgery. Br J Surg 2000;87:86-91.

111. Mayberry JC, Moneta GL, Taylor LM, et al. Fifteen year results of ambulatory compression therapy for chronic venous ulcers. Surg 1991;109:575-81.

112. Callam MJ, Harper DR, Dale JJ, et al. Chronic ulcer of the leg: clinical history. BMJ 1987;294:1389-91.

113. Lang W. Die Entwicklung der perforansvenenchirurgie vom offenen verfahren nach Linton und Cockett zur endoskopischen dissektion. Zentralblad Chir 2001;126:495-500.

114. Dijk va LC, Wittens CH, Toonder IM, et al. Ultrasound-guided percutaneous embolization of incompetent perforating veins: not effective for treatment of venous ulcers and recurrent varicosities. J Vasc Interv Radiol 1999;10:1271-4.

115. Baccaglini U, Spreafico G, Castoro L, et al. Sclerotherapy of varicose veins of the lower limbs. Dermatol Surg 1996;22: 883-9.

116. Noppeney TH, Noppeney J, Scheidt A, et al. Indication und technik zur sclerotherapie bei varikose. Zentral Bl Chir 2001;126:546-50.

117. Schadeck M Die Duplex-controlierte sklerosierungsbehandlung. Phlebologie 2001;30:94-100.

118. Schadeck M. Sclerotherapy des perforantes jambieres. Phlebologie 1997;4:683-8.

119. Dejode LR. Injection-compression treatment of varicose veins. $\mathrm{Br}$ J Surg 1970;57:285-6.

120. Biegeleisen K, Neilsen RD, O’Shaughnessy A. Inadvertent intraarterial injection complicating ordinary and ultrasound guided sclerotherapy. J Dermatol Surg Oncol 1993;19:953-8.

121. Isaacs MN. Duplex-guided sclerotherapy. Dermatol Surg 1997;23:309.

122. Green D. Sclerotherapy for the permanent eradication of varicose veins: theoretical and practical considerations. J Am Acad Dermatol 1998;38:461-75.

123. Perrin MR, Guex JJ, Ruckley CV, et al. Recurrent varices after surgery (REVAS) a consensus document. Cardiovasc Surg 2000;4:233-45.

treatment techniques. In addition, this monograph presents what may be the most logical and succinct classification protocol to date. The authors are to be congratulated.

David M. DufFy, MD

Torrance, CA 